Brief communication

\title{
Hypermethylation of Wnt antagonist gene promoters and activation of Wnt pathway in myelodysplastic marrow cells
}

\author{
Erico Masala ${ }^{\mathrm{a}, 1}$, Ana Valencia ${ }^{\mathrm{a}, 1}$, Francesca Buchi $^{\mathrm{a}}$, Daniele Nosi ${ }^{\mathrm{b}}$, Elena Spinelli ${ }^{\mathrm{a}}$, Antonella Gozzini $^{\mathrm{a}}$, \\ Francesca Sassolini ${ }^{a}$, Alessandro Sanna ${ }^{a}$, Sandra Zecchi ${ }^{b}$, Alberto Bosi ${ }^{a}$, Valeria Santini ${ }^{a}{ }^{*}$ \\ a UF Ematologia, Azienda Ospedaliero Universitaria Careggi, University of Florence, Florence, Italy \\ ${ }^{\mathrm{b}}$ Department of Human Anatomy, University of Florence, Italy
}

\section{A R T I C L E I N F O}

\section{Article history:}

Received 27 February 2012

Received in revised form 24 April 2012

Accepted 27 May 2012

Available online 27 June 2012

\section{Keywords:}

MDS

Methylation

Wnt pathway

Wnt antagonists

$\beta$-Catenin

Azacitidine

\begin{abstract}
A B S T R A C T
We observed aberrant gene methylation of Wnt antagonists: sFRP1, sFRP2, sFRP4, sFRP5 and DKK1 in marrow cells of 55 MDS cases. Methylation of Wnt antagonist genes was associated with activation of the Wnt signaling pathway, consistent with the up-regulation of the Wnt downstream genes TCF1 and LEF1. Azacitidine exposure induced demethylation of Wnt-antagonist gene promoters and reduction of the non-phosphorylated $\beta$-catenin (NPBC) which is prevalent during Wnt pathway inactivation. Presence of $\geq 5 \%$ of bone marrow blasts was associated with methylation of $S F R P 1$ and DKK1 and with methylation of more than two of the five Wnt antagonist genes.
\end{abstract}

(c) 2012 Elsevier Ltd. All rights reserved.

\section{Introduction}

Alterations of the Wnt pathway have been implicated in the pathogenesis of myelodysplastic syndromes (MDS) [1,2]. Activation of the Wnt pathway results in the accumulation of non-phosphorylated $\beta$-catenin (NPBC). After translocation in the nucleus, NPBC associates with the T-cell factor (TCF1)/lymphoidenhancing factor (LEF1) transcription factors, which modulate the expression of Wnt target genes [3]. This pathway is regulated tightly by members of several families of secreted antagonists that interfere with ligand-receptor interactions, such as members of the secreted frizzled-related protein (sFRP) family and the Dickkopf (DKK) family.

High levels of expression of NPBC have been reported in MDS to be related to higher IPSS scores but yet downstream molecular alterations are not clarified [1]. In acute leukemias, the functional loss of Wnt antagonists by aberrant methylation contributes to the activation of the Wnt pathway [4,5]. Interestingly, using a genome wide approach, Wnt antagonists were found aberrantly

\footnotetext{
* Corresponding author at: Functional Unit of Haematology, AOU Careggi, University of Florence, Largo Brambilla 3, 50134 Florence, Italy. Tel.: +39 0557947296; fax: +390557947343.

E-mail address: santini@unifi.it (V. Santini)

1 These authors have contributed equally to this work.
}

methylated in MDS [6]. It can thus be speculated that the functional loss of expression of Wnt antagonists by hypermethylation could be contributing to alteration of Wnt pathway in MDS.

In this study, we analyzed the role of aberrant gene methylation of the $S F R P 1, s F R P 2, s F R P 4, s F R P 5$ and DKK1 genes in the activation of the Wnt pathway in MDS.

\section{Methods and patients}

\subsection{Patients}

Bone marrow (BM) samples were obtained from 55 patients diagnosed with MDS at the Haematology Unit, AOU Careggi, Florence, Italy. Informed consent was obtained according to institutional guidelines. Patient's characteristics are summarized in Table 1

. MDS diagnosis was made in accordance to the WHO criteria. Three CMML were diagnosed according to FAB classification and are included in the study. In our series, 48/55 cases were classified into low/intermediate-1 IPSS risk.

\subsection{Methylation-specific polymerase chain reaction}

After bisulfite conversion, methylation of $s F R P 1, s F R P 2$, sFRP4, SFRP5 and DKK1 genes was assessed by methylation-specific polymerase chain reaction. DNA from monocular cells of healthy 
Table 1

Main characteristics of the patients.

\begin{tabular}{|c|c|c|c|c|c|c|c|c|c|c|}
\hline \multirow[t]{3}{*}{ Characteristics } & \multicolumn{4}{|l|}{$s F R P 1$} & \multirow[t]{3}{*}{$P$-value } & \multicolumn{4}{|l|}{$s F R P 2$} & \multirow[t]{3}{*}{$P$-value } \\
\hline & \multicolumn{2}{|l|}{ Unmethylated } & \multicolumn{2}{|l|}{ Methylated } & & \multicolumn{2}{|l|}{ Unmethylated } & \multicolumn{2}{|l|}{ Methylated } & \\
\hline & Median (range) & $n(\%)$ & Median (range) & $n(\%)$ & & Median (range) & $n(\%)$ & Median (range) & $n(\%)$ & \\
\hline Age, years & $71(43-90)$ & & $76(57-90)$ & & 0.14 & $70(43-86)$ & & $78(36-90)$ & & 0.15 \\
\hline \multicolumn{11}{|l|}{ Sex } \\
\hline Male & & $15(58)$ & & $18(62)$ & 0.71 & & $16(67)$ & & $17(55)$ & 0.2 \\
\hline Female & & $11(42)$ & & $11(38)$ & & & $8(33)$ & & $14(45)$ & \\
\hline Hemoglobin, $\mathrm{g} / \mathrm{L}$ & $10.5(7-14)$ & & $10.9(7-14)$ & & 0.13 & $10(7-14)$ & & $11(7-14)$ & & 0.06 \\
\hline ANC, $10^{9} / \mathrm{L}$ & $1.63(0.3-99)$ & & $1.9(0.4-50)$ & & 0.2 & $1.8(0.2-11.2)$ & & $1.46(0.6-50)$ & & 0.72 \\
\hline Platelets, $10^{9} / \mathrm{L}$ & $138(25-308)$ & & $34(30-393)$ & & 0.3 & $110(25-336)$ & & $117(33-393)$ & & 0.35 \\
\hline \multicolumn{11}{|l|}{ WHO } \\
\hline 5q-syndrome & & $1(4)$ & & $1(3)$ & & & $1(4)$ & & $1(3)$ & \\
\hline $\mathrm{RA}$ & & $10(38)$ & & $6(21)$ & & & $9(38)$ & & $7(22)$ & \\
\hline RARS & & $1(4)$ & & $3(10)$ & 0.35 & & $2(8)$ & & $2(7)$ & 0.22 \\
\hline RCDM & & $10(38)$ & & $8(28)$ & & & $9(38)$ & & $9(29)$ & \\
\hline RAEB & & $3(12)$ & & $7(25)$ & & & $6(4)$ & & $4(29)$ & \\
\hline $\mathrm{CMML}^{\mathrm{a}}$ & & 0 & & $3(10)$ & & & $2(8)$ & & $1(3)$ & \\
\hline \multicolumn{11}{|l|}{ IPSS } \\
\hline Low & & $11(42)$ & & $14(48)$ & 0.6 & & $10(42)$ & & $15(48)$ & 0.67 \\
\hline Intermediate-1 & & $13(50)$ & & $11(38)$ & & & $12(50)$ & & $12(39)$ & \\
\hline Intermediate-2/high & & $2(8)$ & & $4(14)$ & & & $2(8)$ & & $4(13)$ & \\
\hline \multicolumn{11}{|l|}{ Bone marrow blasts } \\
\hline$<5 \%$ & & $20(64)$ & & $4(27)$ & 0.03 & & $17(55)$ & & $5(33)$ & 0.22 \\
\hline $5 \%$ & & $11(36)$ & & $11(73)$ & & & $14(45)$ & & $10(67)$ & \\
\hline \multirow[t]{3}{*}{ Characteristics } & \multicolumn{4}{|l|}{$s F R P 4$} & $P$-value & \multicolumn{4}{|l|}{ sFRP5 } & $P$-value \\
\hline & \multicolumn{2}{|l|}{ Unmethylated } & \multicolumn{2}{|l|}{ Methylated } & & \multicolumn{2}{|l|}{ Unmethylated } & \multicolumn{2}{|l|}{ Methylated } & \\
\hline & Median (range) & $n(\%)$ & Median (range) & $n(\%)$ & & Median (range) & $n(\%)$ & Median (range) & $n(\%)$ & \\
\hline Age, years & $71.3(43-90)$ & & $75(57-90)$ & & 0.15 & $71(40-90)$ & & $77(56-90)$ & & 0.15 \\
\hline Sex & & & & & & & & & & \\
\hline Male & & $27(64)$ & & $6(46)$ & 0.31 & & $25(66)$ & & $8(47)$ & 0.28 \\
\hline Female & & $15(36)$ & & $7(54)$ & & & $13(34)$ & & $9(53)$ & \\
\hline Hemoglobin, $\mathrm{g} / \mathrm{L}$ & $10.75(7-14)$ & & $9.6(7-14)$ & & 0.13 & $10.5(7-14)$ & & $11(7-14)$ & & 0.72 \\
\hline ANC, $10^{9} / \mathrm{L}$ & $1.63(0.2-11.2)$ & & $1.9(0.3-50)$ & & 0.1 & $1.7(0.3-20)$ & & $1.85(0.4-50)$ & & 0.74 \\
\hline Platelets, $10^{9} / \mathrm{L}$ & $110(25-308)$ & & $192(33-193)$ & & 0.27 & $117(25-304)$ & & $143(33-393)$ & & 0.6 \\
\hline WHO & & & & & & & & & & \\
\hline 5q-syndrome & & $1(2)$ & & $1(8)$ & & & $2(5)$ & & 0 & \\
\hline $\mathrm{RA}$ & & $15(37)$ & & $1(8)$ & & & $10(26)$ & & $6(34)$ & \\
\hline RARS & & $2(5)$ & & $2(14)$ & 0.22 & & $3(8)$ & & $1(6)$ & 0,50 \\
\hline RCDM & & $14(33)$ & & $4(31)$ & & & $14(37)$ & & $4(24)$ & \\
\hline RAEB & & $6(14)$ & & $4(31)$ & & & $2(13)$ & & $8(30)$ & \\
\hline $\mathrm{CMML}^{\mathrm{a}}$ & & $3(7)$ & & 0 & & & $3(8)$ & & 0 & \\
\hline IPSS & & & & & & & & & & \\
\hline Low & & $19(45)$ & & $6(46)$ & 0.91 & & $18(47)$ & & $7(41)$ & 0.91 \\
\hline Intermediate-1 & & $18(43)$ & & $6(46)$ & & & $16(42)$ & & $8(47)$ & \\
\hline Intermediate-2/high & & $5(12)$ & & $1(8)$ & & & $4(11)$ & & $2(12)$ & \\
\hline Bone marrow blasts & & & & & & & & & & \\
\hline$<5 \%$ & & $24(77)$ & & $11(73)$ & 1 & & $21(67)$ & & $11(73)$ & 1 \\
\hline $5 \%$ & & $7(23)$ & & $4(27)$ & & & $10(33)$ & & $4(27)$ & \\
\hline
\end{tabular}




\begin{tabular}{|c|c|c|c|c|c|c|c|c|c|c|}
\hline \multirow[t]{3}{*}{ Characteristics } & \multicolumn{4}{|l|}{ DKK1 } & \multirow[t]{3}{*}{$P$-value } & \multicolumn{4}{|c|}{ Methylation profile } & \multirow[t]{3}{*}{$P$-value } \\
\hline & \multicolumn{2}{|l|}{ Unmethylated } & \multicolumn{2}{|l|}{ Methylated } & & \multicolumn{2}{|l|}{ Group A } & \multicolumn{2}{|l|}{ Group B } & \\
\hline & Median (range) & $n(\%)$ & Median (range) & $n(\%)$ & & Median (range) & $n(\%)$ & Median (range) & $n(\%)$ & \\
\hline Age, years & $73(43-89)$ & & $72(56-90)$ & & 0.86 & $71(43-86)$ & & $73(56-90)$ & & 0.57 \\
\hline \multicolumn{11}{|l|}{ Sex } \\
\hline Male & & $15(65)$ & & $18(56)$ & 0.51 & & $12(63)$ & & $21(58)$ & \\
\hline Female & & $8(35)$ & & $14(44)$ & & & $7(37)$ & & $15(42)$ & 0.72 \\
\hline Hemoglobin, g/L & $10.05(7-14)$ & & $10.7(7-14)$ & & 0.23 & $10.4(7-14)$ & & $10.7(7-14)$ & & 0.35 \\
\hline ANC, $10^{9} / \mathrm{L}$ & $1.74(0.4-7.1)$ & & $1.66(0.2-50)$ & & 0.66 & $1.7(0.2-7)$ & & $1.8(0.9-50)$ & & 0.86 \\
\hline Platelets, $10^{9} / \mathrm{L}$ & $110(25-308)$ & & $115(30-393)$ & & 0.62 & $110(25-308)$ & & $117(34-393)$ & & 0.96 \\
\hline \multicolumn{11}{|l|}{ WHO } \\
\hline 5q-syndrome & & $1(4)$ & & $1(3)$ & & & $1(6)$ & & $1(3)$ & \\
\hline $\mathrm{RA}$ & & $9(39)$ & & $7(22)$ & & & $9(47)$ & & 7 (19) & \\
\hline RARS & & $1(4)$ & & $3(10)$ & 0.36 & & 0 & & $4(11)$ & \\
\hline RCDM & & $9(39)$ & & $9(28)$ & & & $9(47)$ & & $9(25)$ & 0.21 \\
\hline RAEB & & $2(10)$ & & $8(25)$ & & & 0 & & $10(28)$ & \\
\hline $\mathrm{CMML}^{\mathrm{a}}$ & & 0 & & $3(9)$ & & & 0 & & $3(8)$ & \\
\hline \multicolumn{11}{|l|}{ IPSS } \\
\hline Low & & $10(44)$ & & $15(47)$ & & & $8(42)$ & & $17(47)$ & \\
\hline Intermediate-1 & & $11(48)$ & & $13(41)$ & 0.83 & & $10(53)$ & & $14(39)$ & 0.48 \\
\hline Intermediate-2/high & & $2(9)$ & & $4(12)$ & & & $1(5)$ & & $5(14)$ & \\
\hline \multicolumn{11}{|l|}{ Bone marrow blasts } \\
\hline$<5 \%$ & & $17(55)$ & & $3(20)$ & 0.03 & & $16(52)$ & & $2(13)$ & \\
\hline $5 \%$ & & $14(45)$ & & $2(80)$ & & & $15(48)$ & & $13(87)$ & 0.02 \\
\hline
\end{tabular}

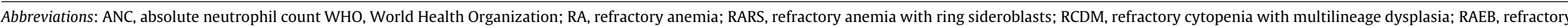
anemia with excess blasts; CMML, chronic myelomonocytic leukemia; IPSS, International Prognostic Scoring System.

a CMML patients were not included in the analysis of the association of Wnt antagonist genes and WHO classification. 
A)

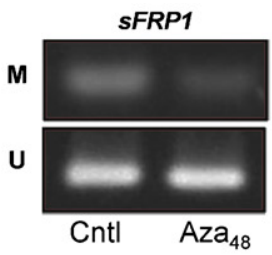

\section{B)}

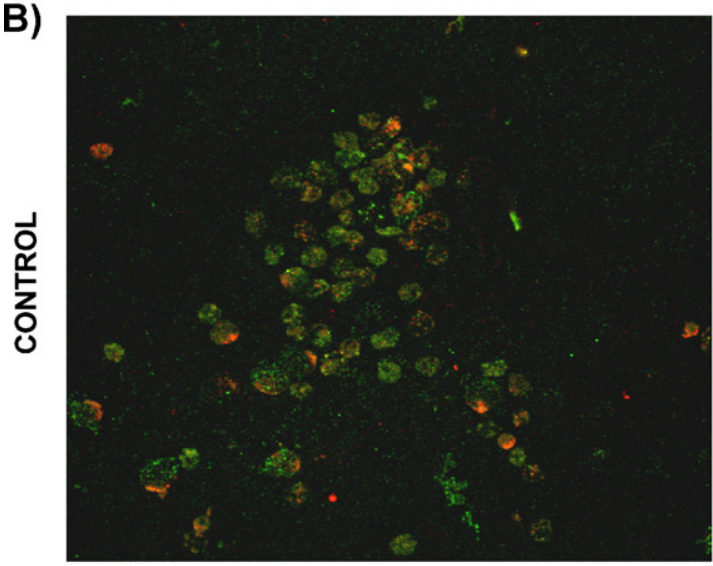

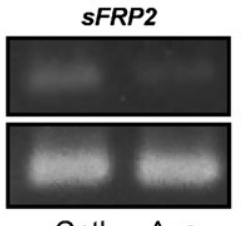

Cntl $\quad \mathrm{Aza}_{48}$
sFRP4

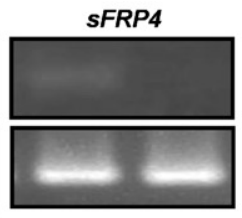

Cntl $\quad \mathrm{Aza}_{48}$

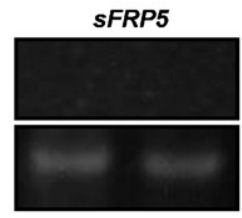

Cntl $\quad \mathrm{Aza}_{48}$
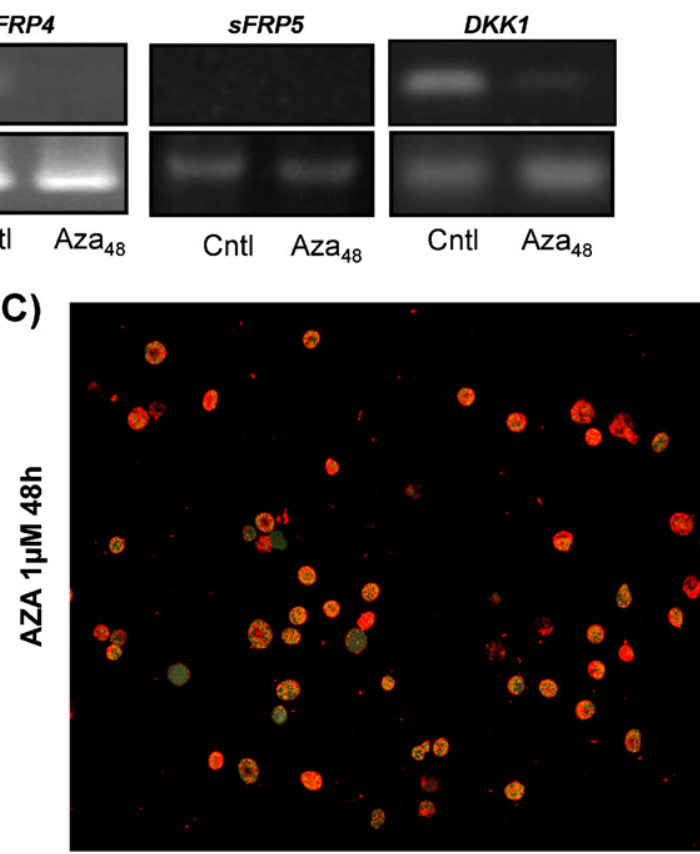

D)

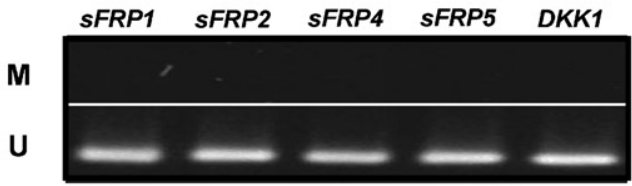

E)

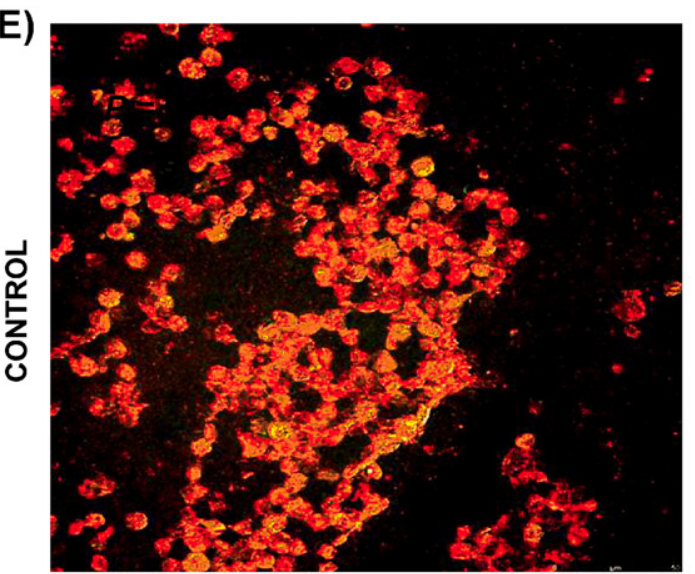

G)

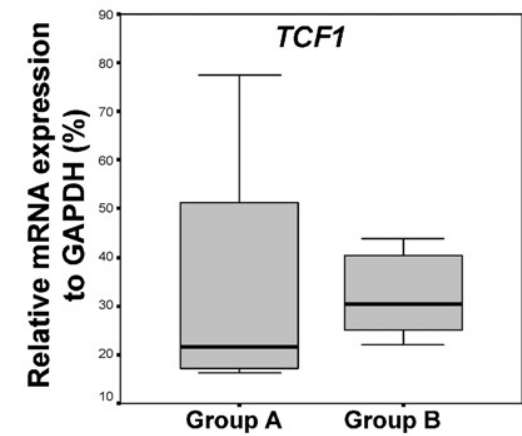

F)
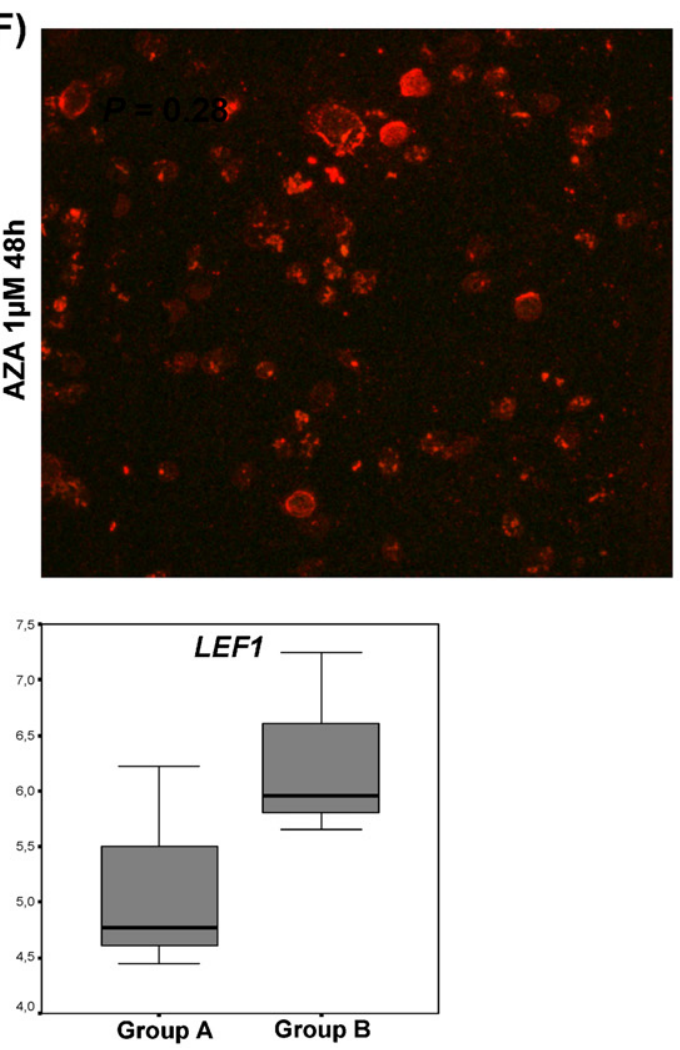

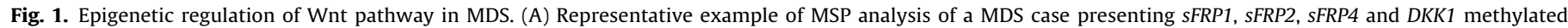

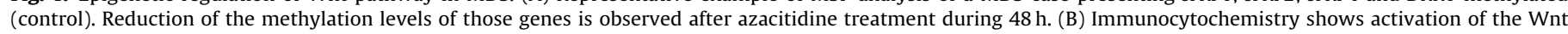

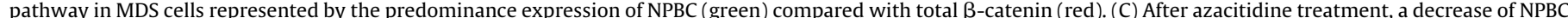

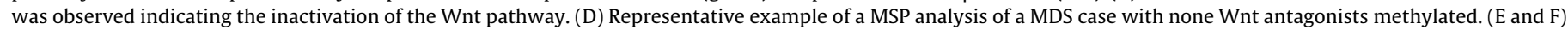

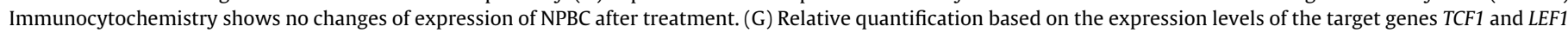

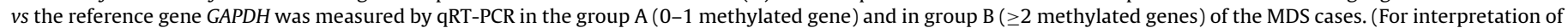
the references to color in this figure legend, the reader is referred to the web version of the article.) 
donors was used as negative control and methylated control DNA (CpGenome Universal Methylated DNA Intergen, USA) was used as positive control. The PCR conditions for all primer sets were as follows: hot start of $95^{\circ} \mathrm{C}$ for $10 \mathrm{~min}, 95^{\circ} \mathrm{C}$ for $1 \mathrm{~min}, 54-60^{\circ} \mathrm{C}$ (depending on the primer set) for $1 \mathrm{~min}$, and $72^{\circ} \mathrm{C}$ for $1 \mathrm{~min}$ for 35 cycles and a final extension at $72^{\circ} \mathrm{C}$ for $10 \mathrm{~min}$.

\subsection{Treatment with 5-azacytidine}

For in vitro experiments, bone marrow mononuclear cells (BMMC) were separated by standard density gradient centrifugation. BMMC were cultured at a density of $0.3 \times 10^{6} \mathrm{cells} / \mathrm{ml}$, in RPMI 1640 medium with glutamine supplemented with $10 \%$ fetal bovine serum and maintained and treated for $48 \mathrm{~h}$ with $1 \mu \mathrm{M}$ azacitidine (5-azacytidine, Sigma-Aldrich) added daily.

\subsection{Immunocytochemistry}

The presence of active $\beta$-catenin was determined by immunocytochemistry using the following antibodies: anti-NPBC (1:200; Millipore, USA) and anti-total $\beta$-catenin (1:250; Sigma-Aldrich, USA). After washing, the immunolabeled cells were observed under a Bio-RadMRC1024 ES confocal laser scanning microscope (CLSM; Bio-Rad).

\subsection{Expression analysis}

Quantitative reverse transcription-PCR was performed with the ABI GeneAmp ${ }^{\circledR} 5700$ (Applied Biosystems, CA). We used primers for TCF1 and LEF1 genes previously reported [5] and GAPDH as internal control. Reactions were done with the SYBR ${ }^{\circledR}$ PCR Master Mix (Applied Biosystems) to detect gene expression. Each sample was measured in triplicate.

\subsection{Statistical analysis}

We applied Mann-Whitney nonparametric $U$-test, $\chi^{2}$-test and Fisher's exact test. All test were performed using the statistical package SPSS, version 17.0 (SPSS Inc., Chicago, USA). $P$-value $\leq 0.05$ was considered significant.

\section{Results}

\subsection{Methylation status of Wnt antagonists}

Aberrant methylation was observed in all genes analyzed: $50 \%$ for $s F R P 2,60 \%$ for $s F R P 1,48 \%$ for DKK1, 32\% for $s F R P 5$ and $22 \%$ sFRP4. Presence of aberrant methylation of Wnt antagonist genes was detected in all samples, independently from IPSS score or WHO subtypes. After classifying cases according to the number of methylated genes per individual sample, 19 MDS cases (34\%) were included in group A (0-1 methylated gene) and 36 MDS cases (66\%) in group $\mathrm{B}$ ( $\geq 2$ methylated genes). Aberrant DNA methylation of individual genes was not significantly associated with clinical characteristics like age, sex, hemoglobin level, absolute neutrophil count, platelet count, WHO classification and IPSS score. Only aberrant methylation of $S F R P 1$ and DKK1 methylation was detected more frequently in cases with $\geq 5 \%$ of marrow blasts $(P=0.03$ for both; Table 1$)$. Additionally, cases with $\geq 5 \%$ of marrow blasts belonged with significant higher frequency to group $\mathrm{B}(P=0.02)$ (Table 1$)$.

\subsection{Modifications of Wnt pathway activation}

To investigate the consequences of aberrant methylation of Wnt antagonists in the regulation of the Wnt pathway, we analyzed the methylation status of Wnt antagonists as well as the expression of NPBC after azacitidine in vitro. Immunocytochemistry analysis showed that MDS cases with methylated Wnt antagonists (Fig. 1A) presented an abundant NPBC in the nucleus of marrow cells (Fig. 1B). After treatment, hypomethylation of Wnt antagonists was observed (Fig. 1A). In parallel, a reduction of NPBC in the nucleus was observed, indicating that activated Wnt pathway in MDS depends on silencing by hypermethylation of Wnt antagonists (Fig. 1C). On the other hand, MDS cases with unmethylated Wnt antagonists (Fig. 1D) showed scarce presence of NPBC, which did not apparently change after treatment with azacitidine (Fig. 1E and F). To confirm the effects of aberrant hypermethylation of Wnt antagonists in vivo, we measured the expression of downstream components of the Wnt pathway. As expected, the transcript levels of TCF1 (median, $21.6 \%$ vs 30.4\%, $P=0.46$; Fig. $1 G$ ) and LEF1 (6.2\% vs $5.9 \%, P=0.28$; Fig. $1 G$ ) were higher in group $B$ than in group $A$.
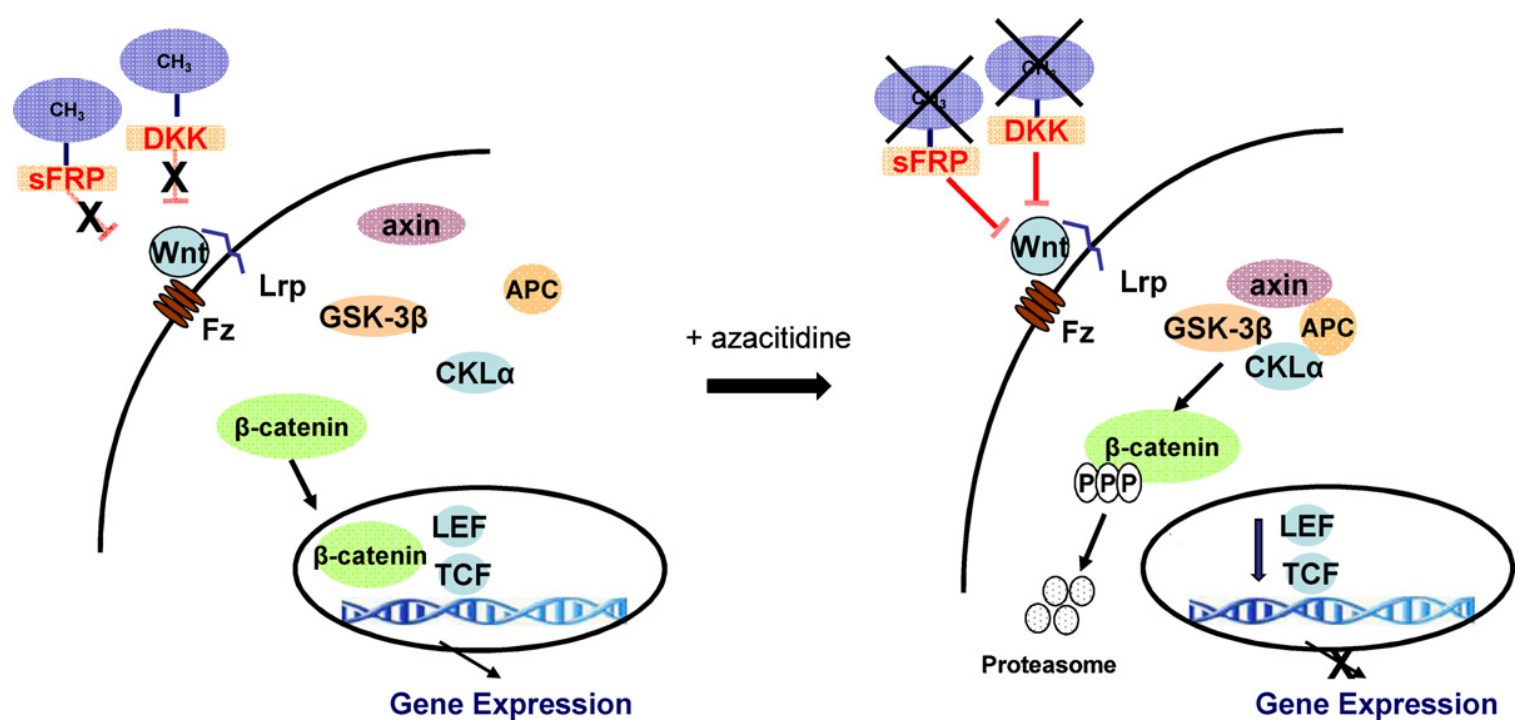

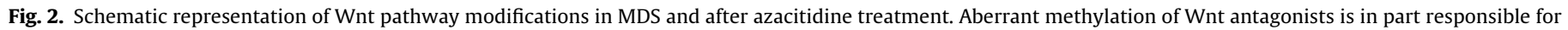

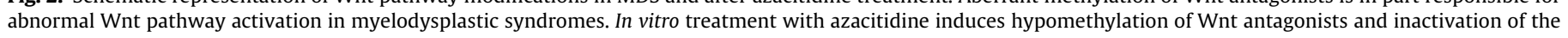
Wnt pathway, by downregulating the Wnt downstream genes TCF1 and LEF1 and reducing nuclear localization of $\beta$-catenin. 
This trend did not achieve statistical significance, possibly because of small sample size.

\section{Discussion}

We analyzed almost exclusively IPSS low risk MDS cases, and, although methylation of $S F R P 1$ and DKK1 promoters was significantly more frequent in patients with $\geq 5 \%$ of bone marrow blasts, we observed a high incidence of aberrant DNA methylation of the promoters of Wnt antagonist genes, comparable to that previously demonstrated by some of us in AML [5]. IPSS low risk MDS cases are less prone to progress to AML, and show a minor frequency of general aberrant methylation [7], which usually increases in parallel with disease progression. Our findings are thus suggesting that the activation of Wnt signaling may play a critical and fundamental role in the pathogenesis of MDS, being present in early stages of the disease.

Figueroa et al. [6] showed in MDS and AML that genes involved in Wnt and MAPK signaling pathways were hypermethylated and among those were Wnt antagonists, sFRP1, sFRP2 and sFRP3 genes. However, our results are not completely consistent with those of other authors, as SFRP1 was also found silenced (further support to the importance of this pathway in MDS), but rarely by hypermethylation [8]. In the present study, in fact, about $52 \%$ of the MDS cases showed methylation of at least one of the five genes studied. In acute leukemias, strong evidence of a relationship between hypermethylation of Wnt antagonist genes and activation of Wnt signaling has been provided [4,5]. Here, methylation of Wnt antagonist genes was associated with activation of the Wnt pathway, as demonstrated by the up-regulation of TCF1 and LEF1 genes. Moreover, treatment in vitro with the hypomethylating agent azacitidine induced demethylation of Wnt antagonist gene-promoters and functional inactivation of the Wnt pathway, with clear reduction of NPBC in the nucleus (Fig. 2). Our data imply a pivotal role of Wnt pathway in MDS development, and, in our view, suggest a possible specific basis of azacitidine efficacy in IPSS low risk MDS.

\section{Conflict of interest statement}

All authors have no conflict of interest to declare.

\section{Acknowledgements}

Research fundings: Regione Toscana, Bando Salute 2009; Ente Cassa di Risparmio di Firenze (ECR); Ministero per l'Istruzione, l'Università e la Ricerca (MIUR).

Contributors: VS designed the study and wrote the manuscript; $\mathrm{EM}$ and $\mathrm{AV}$ preformed experiments and wrote the results section; FB and ES performed experiments; DN performed confocalmicroscopy analysis; AS, AG, FS collected samples, clinical and biological data; $A B$ and $S Z$ discussed data and contributed to manuscript writing. All authors reviewed and gave final approval to the manuscript.

\section{References}

[1] Xu J, Suzuki M, Niwa Y, Hiraga J, Nagasaka T, Ito M, et al. Clinical significance of nuclear non-phosphorylated beta-catenin in acute myeloid leukemia and myelodysplastic syndrome. Br J Haematol 2008;140:394-401.

[2] Pellagatti A, Cazzola M, Giagounidis A, Perry J, Malcovati L, Della Porta MG, et al. Deregulated gene expression pathways in myelodysplastic syndrome hematopoietic stem cells. Leukemia 2010;24:1062-5.

[3] Wodarz A, Nusse R. Mechanisms of Wnt signaling in development. Annu Cell Dev Biol 1998;14:59-88.

[4] Román-Gómez J, Cordeu L, Agirre X, Jiménez-Velasco A, San José-Eneriz E, Garate $\mathrm{L}$, et al. Epigenetic regulation of Wnt-signaling pathway in acute lymphoblastic leukemia. Blood 2007;109:3462-9.

[5] Valencia A, Román-Gómez J, Cervera J, Such E, Barragán E, Bolufer P, et al. Epigenetic regulation of Wnt pathway by aberrant hypermethylation of Wnt antagonists in acute myeloid leukemia. Leukemia 2009;23:1658-66.

[6] Figueroa ME, Skrabanek L, Li Y, Jiemjit A, Fandy TE, Paietta E, et al. MDS and secondary AML display unique patterns and abundance of aberrant DNA methylation. Blood 2009;114:3448-58.

[7] Jiang Y, Dunbar A, Gondek LP, Mohan S, Rataul M, O'Keefe C, et al. Aberrant DNA methylation is a dominant mechanism in MDS progression to AML. Blood 2009;113:1315-25.

[8] Reins J, Mossner M, Neumann M, Platzbecker U, Schumann C, Thiel E, et al. Transcriptional down-regulation of the Wnt antagonist SFRP1 in haematopoietic cells of patients with different risk types of MDS. Leuk Res 2010;34:1610-6. 